\title{
Morphological, Structural and Optical Properties of ZnO Thin Films Deposited by Dip Coating Method
}

\author{
Sara Marouf $f^{4}$, Abdelkrim Beniaiche ${ }^{a}$, Hocine Guessas ${ }^{a}$, Amor Azizi ${ }^{b}$ * \\ ${ }^{a}$ Laboratoire des Systèmes Photoniques et Optiques Non Linéaires, Institut d'Optique et Mécanique de \\ Précision, Université Ferhat Abbas-Sétif 1, 19000 Sétif, Algeria \\ ${ }^{b}$ Laboratoire de Chimie, Ingénierie Moléculaire et Nanostructures, Université Ferhat Abbas-Sétif 1, \\ 19000 Sétif, Algeria
}

Received: December 8, 2015; Revised: August 16, 2016; Accepted: September 7, 2016

\begin{abstract}
Zinc oxide $(\mathrm{ZnO})$ thin films were deposited on glass substrat by dip coating technique. The effects of sol aging time on the deposition of $\mathrm{ZnO}$ films was studied by using the field emission scanning electron microscopy (FE-SEM), atomic force microscopy (AFM), X-ray diffraction (XRD), and optical transmission techniques. The morphology of the films strongly depends on preparation route and deposition technique. It is noteworthy that films deposited from the freshly prepared solution feature indistinct characteristics; had relatively poor crystalline quality and low optical transmittance in the visible region. The increase in sol aging time resulted in a gradual improvement in crystallinity (in terms of peak sharpness and peak intensity) of the hexagonal phase for all diffraction peaks. Effect of sol aging on optical transparency is quite obvious through increased transmission with prolonged sol aging time. Interestingly, $72-168 \mathrm{~h}$ sol aging time was found to be optimal to achieve smooth surface morphology, good crystallinity and high optical transmittance which were attributed to an ideal stability of solution. These findings present a better-defined and more versatile procedure for production of clean $\mathrm{ZnO}$ sols of readily adjustable nanocrystalline size.
\end{abstract}

Keywords: $\mathrm{ZnO}$, characterization, thin films, sol aging time, optical properties.

\section{Introduction}

For a decade, there has been a great growing interest in nanomaterials because of its distinguishable difference in properties from macroscopic and bulk materials. Research in this area has focused on the synthesis, characterizations and applications of nanometer-sized metals, semiconductors and ceramics ${ }^{1}$. Indeed, designing nanomaterials is a critical issue for industrial applications, because the properties of nanomaterials play a significant role on the performance of devices ${ }^{2}$. Particularly, $\mathrm{ZnO}$ nanostructures have been studied intensively and extensively over the last decade not only for their remarkable chemical and physical properties, but also for their diverse current and future technological applications. They possess several interesting properties such as optical transparency, electrical conductivity, piezoelectricity, nontoxicity, wide availability, low cost and chemical stability ${ }^{3-5}$. $\mathrm{ZnO}$ is used as transparent electrodes, photocatalysts, energy saving coating materials for window glasses, acousto-optic devices, ferroelectric memories, reduction gas detection sensors $^{6}$ and solar cells ${ }^{7}$. So far, $\mathrm{ZnO}$-based thin films have been prepared by many different techniques based on vacuum deposition and solution-based processes ${ }^{8}$. While physical methods are capable of producing high-quality, single-crystalline nanostructures, these processes run

* e-mail: aziziamor@yahoo.fr into some deterrents notably, high-temperature-synthesis, ultra-high vacuum in some cases, and other restrictions in terms of sample uniformity, substrate choice, and low product yield. On the contrary, the chemical processes do not undergo these drawbacks and are capable of producing unconventional shapes and structures ${ }^{9}$. A wide variety of chemical methods have been reported in the literature such as chemical bath deposition $(\mathrm{CBD})^{10}$, electrodeposition ${ }^{11-15}$, hydrothermal ${ }^{16}$, spray pyrolysis ${ }^{17}$, ultrasonic spray pyrolysis ${ }^{18}$ and co-precipitation method ${ }^{19}$. Compared with the above methods, sol-gel method is the most widely used due to its high versatility, simplicity, low equipment cost, the ability of accurate control of stoichiometry over the molecular level mixing, large area coating, high homogeneity and relatively low process temperature ${ }^{20-22}$. Although the sol-gel method is a relatively simple technique for depositing $\mathrm{ZnO}$ thin films, there are still some factors affecting the properties of the prepared films. The factors including sol aging time, sol concentration $^{23}$, heat-treatment conditions, substrate ${ }^{24}$, film thickness $^{25}$, dopants ${ }^{26}$, pH of solution ${ }^{27}$, solvents ${ }^{28}$ and chelating agents $^{9}$ have been under continuous investigation. Among the deposition parameters mentioned; sol aging time is an important parameter which can have remarkable impact on thin films properties. Heretofore, the promising effects of $\mathrm{ZnO}$ sol aging time in terms of crystallinity and reaction-assisting are somehow described in previous reports ${ }^{29}$. However, to 
the best of our knowledge, no study has ever been done before concerning effects of sol aging time on the sol-gel behavior and the properties of sol-gel derived undoped $\mathrm{ZnO}$ thin films deposited by dip coating route. In this context, an attempt was made to investigate the influence of sol aging time on the properties of $\mathrm{ZnO}$ thin film during synthesis process in order to accomplish a better control over growth process. We believe that an appropriate sol aging may be a better choice which will ultimately provide high quality zinc oxide thin film using a simple method.

\section{Experimental Procedure}

\subsection{Materials}

For the preparation of $\mathrm{ZnO}$ sol, the following materials were used zinc acetate dihydrate and methanol. Distilled water was used to rinse substrates. All chemicals were of analytical grade, obtained from commercial sources, used as received without further purification.

\subsection{Films preparation and processing}

Transparent $\mathrm{ZnO}$ thin films were prepared by sol-gel method through dip coating on glass substrates. Specifically, zinc acetate dihydrate was dissolved in methanol under magnetic stirring at $70^{\circ} \mathrm{C}$ for an hour to yield a clear and homogeneous solution of $0.1 \mathrm{M}$. The product was then divided into four equal amounts and stored in four different beakers and aged for different time before deposition (Table 1). The final solutions were kept in the dark at room temperature, in order to avoid some light-assisted reaction that may affect the solution. After underwent an appropriate aging, the precursor was ready to be applied on a glass substrates. Before dipping the substrate into the precursor sol, the glass substrates were properly cleaned ultrasonically initially by acetone then nitric acid and finally with distilled water to remove all contamination which could affect thin film properties.

Film deposition was carried out in air at room temperature by the dip-coating method onto the substrate with a controlled withdrawal speed of $5 \mathrm{~cm} / \mathrm{min}$. They have been deposited from as-prepared as well as the sols aged for long time.
After each coating, the samples were left to dry, to evaporate the solvent and remove organic residuals, on a hot plate at $170^{\circ} \mathrm{C}$ for $15 \mathrm{~min}$ and were held in the horizontal position to avoid draining of the transferred sol, which could lead to different thicknesses in the coatings. The procedures from coating to drying were repeated several times until the film reached the desired thickness. The as-prepared films were then inserted into a furnace and annealed at $500{ }^{\circ} \mathrm{C}$ for an hour in the air and cooled down at room temperature. The atomic force microscopy (AFM) and field emission scanning electron microscope (FE-SEM) are employed to observe the morphology of synthesized samples. The phase structure of $\mathrm{ZnO}$ thin films were analyzed by X-ray diffraction (XRD) technique. XRD measurements were performed on a BRUKER D8 FOCUS diffractometer operating at 35 $\mathrm{kV}$ and $40 \mathrm{~mA}$ using $\mathrm{CoK} \alpha$ radiation $\left(\mathrm{K} \alpha_{1}=1.78901 \AA\right)$. The diffraction patterns were collected over $25-100^{\circ}$ with a step size of $0.02^{\circ}$ and a step time of $33.50 \mathrm{~s}$. The optical transmission spectra were obtained using a UNICAM UV 300 as UV-visible spectrophotometer.

\section{Results and discussions}

\subsection{Chemical reactions}

The growth of $\mathrm{ZnO}$ thin films from zinc acetate dihydrate precursor using sol-gel process generally undergoes four stages, such as solvation and formation of methoxyacetate complexes, hydrolysis (by water originating from $\mathrm{Zn}$ (Ac) $)_{2} 2 \mathrm{H}_{2} \mathrm{O}$ itself), polymerization of the complexes and transformation into $\mathrm{ZnO}$. The size and activity of solvent have obvious influence on the reacting progress and product. Methanol has smaller size and a more active $-\mathrm{OH}$ and $-\mathrm{OCH}_{3}$ groups. It can react more easily to form a polymer precursor with a higher polymerization degree, which is required to convert sol in to gel.

The dissolution of zinc acetate dihydrate accompanies solvation of zinc and acetate ions by methanol (MeOH). Hydrated water molecules form hydrogen bonding with $\mathrm{MeOH}$. The kinetics of hydrolysis and polymerization are greatly influenced by water concentrations in the solutions. The zinc ion has a solvation number of six and forms an octahedral inner coordination sphere, $\left[\mathrm{Zn}(\mathrm{MeOH})_{6}\right]^{2+}$.

Table 1: Effects of sol aging time on the microstructural properties of $\mathrm{ZnO}$ thin films.

\begin{tabular}{|c|c|c|c|c|c|c|}
\hline \multirow{2}{*}{$\begin{array}{l}\text { Aging time } \\
\text { (hour) }\end{array}$} & \multirow{2}{*}{$2 \theta$ (deg.) } & \multirow{2}{*}{$\mathrm{d}(002)(\AA)$} & \multirow{2}{*}{ FWMH (deg.) } & \multirow{2}{*}{$\begin{array}{c}\mathrm{D} \\
(\mathrm{nm})\end{array}$} & \multicolumn{2}{|c|}{ Lattice parameters $(\AA)$} \\
\hline & & & & & $\mathrm{c}$ & $\mathrm{a}$ \\
\hline as-prepared & 40.33 & 2.594 & 0.705 & 13.93 & 5.189 & 2.995 \\
\hline 72 & 40.34 & 2.594 & 0.424 & 23.17 & 5.188 & 2.995 \\
\hline 168 & 40.39 & 2.590 & 0.300 & 32.76 & 5.181 & 2.991 \\
\hline 312 & 40.35 & 2.593 & 0.284 & 34.60 & 5.186 & 2.994 \\
\hline
\end{tabular}


Thus the reaction scheme is invoked as:

$$
\begin{aligned}
& {\left[\mathrm{Zn}(\mathrm{MeOH})_{6}\right]^{+2}+\mathrm{mMeOH}+\mathrm{Ac}^{-} \longleftrightarrow} \\
& {\left[\mathrm{Zn}(\mathrm{MeOH})_{5-m}(\mathrm{MeO})_{m} \mathrm{Ac}\right]^{1-m}+} \\
& \mathrm{mMeOH}_{2}^{+}+\mathrm{MeOH}
\end{aligned}
$$

The formation of the methoxyl group is due to the enhanced acidity of the solvating $\mathrm{MeOH}$ causing the deprotonation by free $\mathrm{MeOH}$. A reaction between the methoxyacetate complexes and water is considered. The water concentration in the solution does not exceed double of the zinc concentration because water was supplied only from the starting material, $\mathrm{Zn}(\mathrm{Ac})_{2} 2 \mathrm{H}_{2} \mathrm{O}$. Therefore the hydrolysis reaction is expected to proceed considerably slowly. At lower water concentrations, water acts as a nucleophilic reactant. The nucleophilic substitution with a leaving group of $\mathrm{MeOH}$ and/or $\mathrm{CH}_{3} \mathrm{COOH}$ leads to hydrolysis of the complexes,

$\left[\mathrm{Zn}(\mathrm{MeOH})_{5-m}(\mathrm{MeO})_{m} \mathrm{Ac}\right]^{1-m}+(m+1) \mathrm{H}_{2} \mathrm{O} \longleftrightarrow$

$\left[\mathrm{Zn}(\mathrm{MeOH})_{5-m}(\mathrm{OH})_{m+1}\right]^{1-m}+m \mathrm{MeOH}+\mathrm{AcH}$

A polymerization reaction between mononuclear complexes generally occurs if at least one hydroxyl group is bounded to the metal ion. The first step of polymerization is the construction of an "ol" bridge in which a hydroxyl group is caught between the two metal ions. Writing the zinc hydroxide complex simply as $\mathrm{Zn}-\mathrm{OH}$, an olation reaction is expressed schematically by:

$\mathrm{Zn}-\mathrm{OH}+\mathrm{OH}-\mathrm{Zn} \longleftrightarrow \mathrm{Zn}-(\mathrm{OH})-\mathrm{Zn}+\mathrm{OH}$

That is, " $\mathrm{Zn}(\mathrm{OH}) \mathrm{Zn}$ ” bridges are formed by an olation reaction resulting in polynuclear zinc hydroxide clusters. When more than one hydroxyl group is brought to the complex, polymerization among the complexes proceeds, generating polynuclear zinc hydroxide clusters. Thus the " $\mathrm{Zn}$ $\mathrm{O} \mathrm{Zn}$ " bonds are constructed and the complexes are finally transformed into solid $\mathrm{ZnO}^{30-32}$ after annealing.

\subsection{Aged sol and coatings}

From visual inspections, the sol remains transparent, stable and indistinguishable from each other, regardless of the aging time. No gelation occurred over an aging period as long as several weeks. Also, films are transparent, homogenous, hard and are crack free. Such films were specularly reflecting and tightly adherent to substrate and could not be removed by abrasion with a tissue.

\subsection{Morphological analysis}

Figure 1 shows FE-SEM images of the $\mathrm{ZnO}$ thin films obtained after different aging time. It's clear from later images that surface morphology is considerably affected by sol aging time. Effectively, the as-prepared film produces
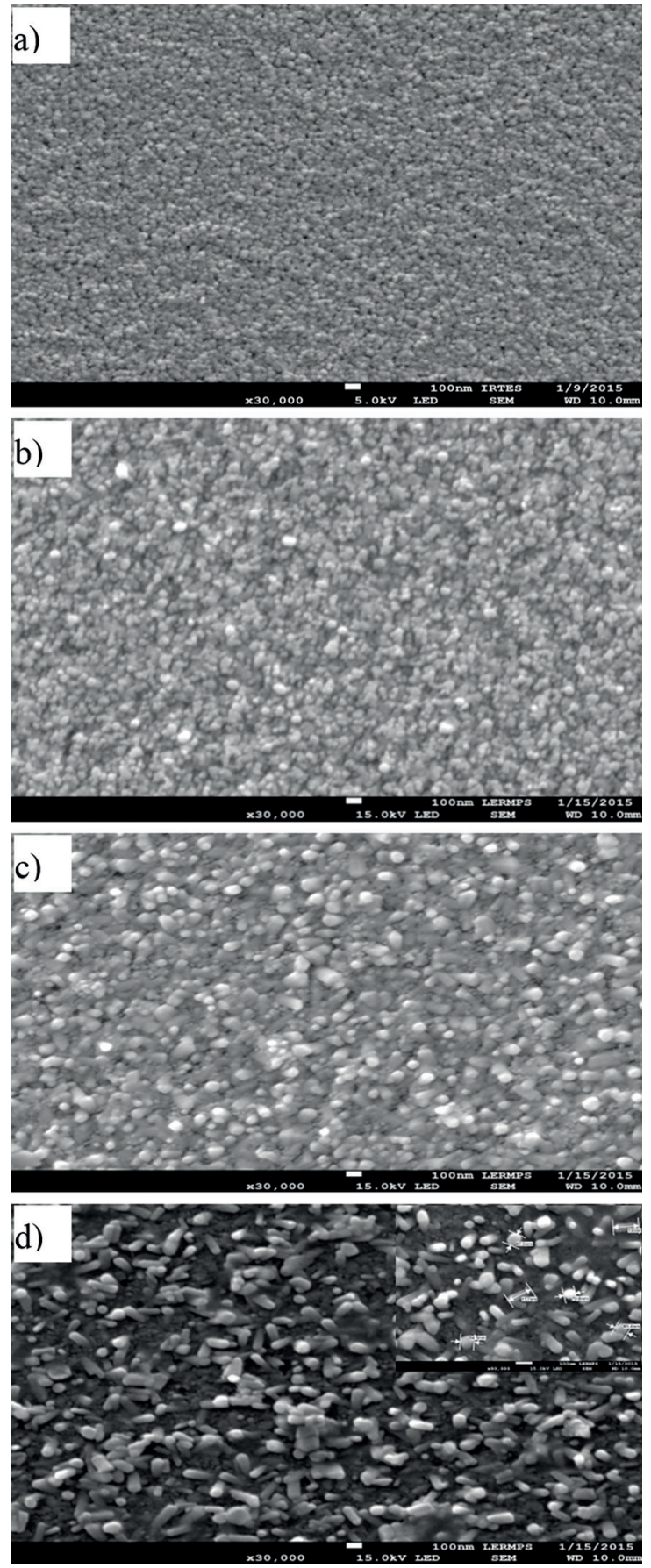

Figure 1: FE-SEM images of the $\mathrm{ZnO}$ thin films for different aging time: a) as-prepared, b) $72 \mathrm{~h}$, c) $168 \mathrm{~h}$, and d) $312 \mathrm{~h}$. The inset shows the magnified surface morphology.

the appearance of a granular structures composed of small grains that appear somehow aggregated with porosity around. After, by increasing the sol aging time, films exhibit a finer texture in which bigger particles formed by nanocrystals agglomerate that are more effectively packed, giving denser structures characterized by lower porosity. For sols reached an aging time as long as 168 and 312 h, 
the $\mathrm{ZnO}$ thin film is composed of vertically aligned densely packed randomly oriented nanorod with diameter in the range 43-87 $\mathrm{nm}$ having various lengths. The results from FE-SEM images are consistent with the observations from XRD. ZnO nanostructures have different orientations with particle size increasing as a function of aging period. Kanade et al. ${ }^{33}$ explained that when a solvent with higher saturated vapor pressure such as methanol is utilized as a reaction media, the amalgamation of the nucleus is not intense due to the lower boiling point of the solvent, which results in mixed spherical and rod like particle morphology in case of methanol mediated $\mathrm{ZnO}$. The aspect ratios (length divided by width) of the nanorods ranges from 1 and $2 \mathrm{~nm}$. Especially, the length of the grain depends on the sol aging time. An average value of about $155 \mathrm{~nm}$ was observed for the samples deposed after sol being aged 312 h, i.e. longer aging time results in higher nanorod length. The differences in the film morphologies can be correlated with the particles shape.

In addition, the film surface morphology and surface roughness were also studied using an AFM technique. Figure 2 displays AFM images in tapping mode of $\mathrm{ZnO}$ thin films deposited from aged sol. It reveals that all films have a smooth surface morphology, and the cracks and pinholes were absent. For scanning area of $5 \times 5 \mu \mathrm{m}^{2}$, the root-mean square (RMS) of average surface roughness for all samples was determined. The measured roughness parameters were 10.67, 5.07, 5.72 and $7.33 \mathrm{~nm}$ for $\mathrm{ZnO}$ films corresponding to the aging time $t=0,72,168$, and $312 \mathrm{~h}$, respectively. From this data, it could be also found that the surface roughness of the films decreased as sol aging time increased then slightly increased for sol aged $312 \mathrm{~h}$. The increase of surface roughness along with sol aging time may be attributed to the larger grain formation and more porosity of the films. Generally, by increasing the sol aging time, more uniform, compact and smoother films were obtained. This is in good agreement with the FE-SEM results. Accordingly, the quality of $\mathrm{ZnO}$ thin films prepared by aged sols is improved.

\subsection{Structural characterization}

The XRD patterns of the deposited $\mathrm{ZnO}$ films as a function of sol aging time are shown in Figure 3. From XRD pattern the polycrystalline nature of the $\mathrm{ZnO}$ films clearly appears. All peaks have been indexed and were found to be in agreement with those of the hexagonal wurtzite phase of $\mathrm{ZnO}$. Either peak position or peak intensity is in good agreement with the data from JCPDS card No. 00-036-1451. Moreover, no other peaks were detected, implying that the prepared nanostructured materials are pure $\mathrm{ZnO}$.

Results indicate that thin film prepared from sol without aging represent bad crystallinity. Similar results were reported by Lie et al..$^{34}$, they attribute it to the stability of the sol, i.e. the as-synthesized sol is not stable enough in which the colloidal-particle sizes and colloidal-particle distribution are non-uniform. As a result, the film deposited by the assynthesized sol has relatively poor quality.

The crystallite size was calculated using the Scherrer formula ${ }^{35}$ :

$$
D=\frac{k \lambda}{\beta \cos \theta}
$$

where $\mathrm{D}, \theta$, and $\lambda$ are the mean crystallites size, the Bragg angle, and the wavelength of the incident X-ray $(0.17889 \mathrm{~nm})$, respectively. $K$ is a shape factor and usually takes a value of 0.94 and $\beta$ is the full-width at half maximum (FWHM) of the diffraction peak.

Table 1 shows the values of crystallites size and other microstructural parameters. From this data it's evident that crystallite size increased significantly with the increment of sol aging time. Also, the calculated lattice constants ' $a$ ' and ' $c$ ' of the prepared films were found to be close to those of pure bulk $\mathrm{ZnO}(\mathrm{a}=3.249 \AA, \mathrm{c}=5.206 \AA)$. It is clearly seen that film crystallinity of the as-synthesized is enhanced by increasing the sol aging time, meaning that more longer aging time promote more grain growth and hence narrower peaks with higher intensities which is evidenced by Figure 4. It is worthwhile to notify that different degrees of crystallinity could be reached regarding the aging time, i.e. the more the sol is aged; the greater is the crystallinity with random orientation. This is consistent with Dutta et al. ${ }^{36}$. Also, Fathollahi et al. ${ }^{37}$ found a threefold increase in the intensity of (002) reflection of zinc oxide films using a 3-week-aged zinc acetate solution in comparison to the freshly prepared solution when all the other variables were kept fixed. Similarly, Singh et al. ${ }^{38}$ synthesized $\mathrm{ZnO}$ nanoparticles via Sol-gel route; they found that the crystallite size as well as the crystallinity of the nanoparticles increased with aging. Ibrahim et al. ${ }^{29}$ observed that by increasing the precursor aging time, an enhancement of the intensity for all diffraction peaks occurs in general. Despite the difference in precursor composition as well as the deposition route, both we and these previous reports found that sol aging time is of paramount importance in the improvement of the crystallinity. But our results are much better which is manifestly demonstrated from the peaks number and sharpness. According to Brinker et al. ${ }^{39}$, chemical reactions that cause gelation continue long after the gel point, producing strengthening, stiffening, and shrinkage of the network. Wright et al. ${ }^{40}$ recognized aging for improvement of material properties, and explained that Shrinkage occurs because new bonds are formed where there were formerly only weak interactions between surface hydroxy and alkoxy groups. This shrinkage leads to expulsion of liquid from the pores of the gel, so that gel samples in sealed containers gradually change in appearance from homogeneous gels to transparent shrunken solid monoliths immersed in liquid. This process is known as synersis. Another process associated with ageing is often referred to 

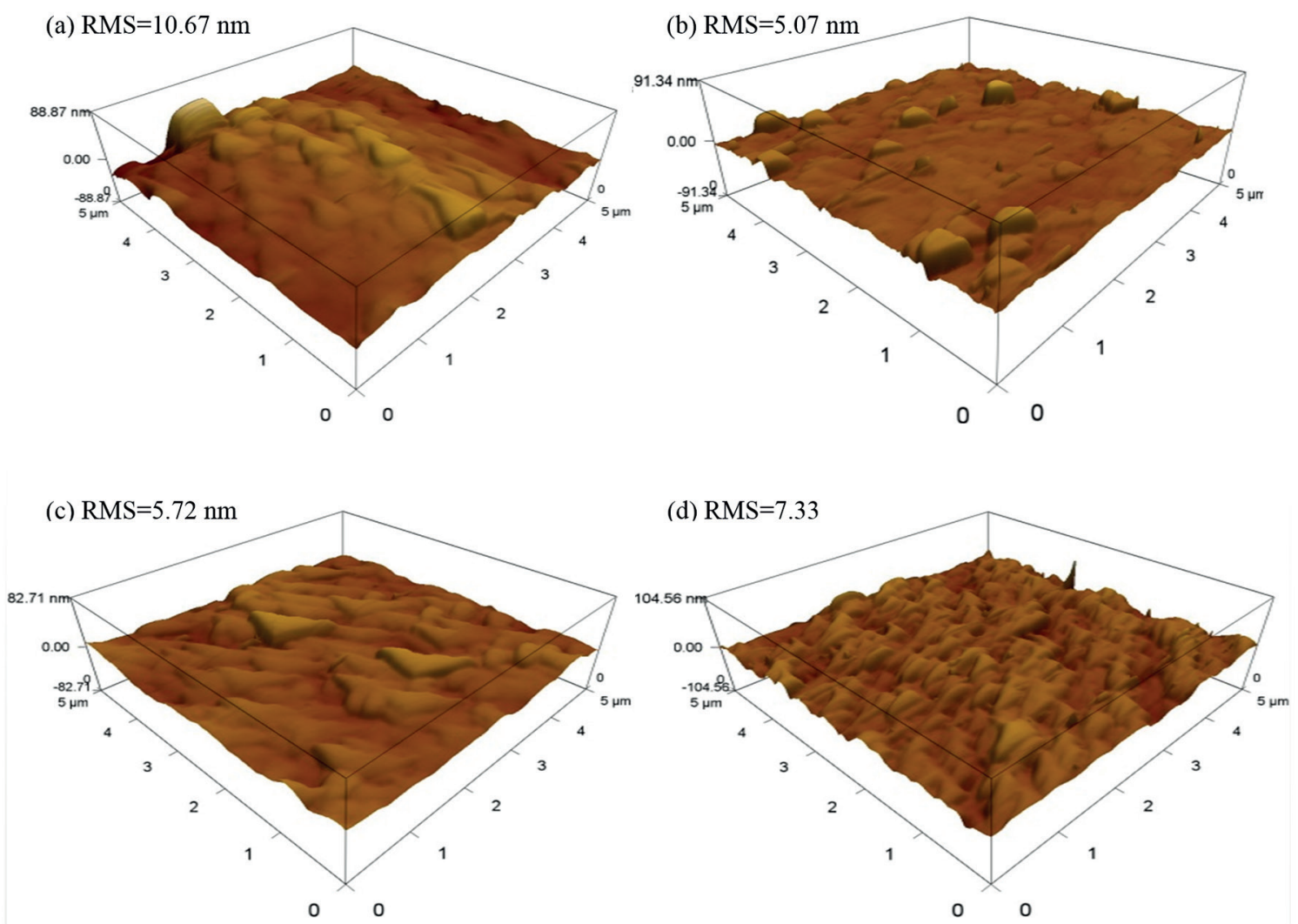

Figure 2: AFM surface morphology images of the $\mathrm{ZnO}$ thin films after different aging time: a) as-prepared, b) $72 \mathrm{~h}, \mathrm{c}) 168 \mathrm{~h}, \mathrm{~d}) 312 \mathrm{~h}$.

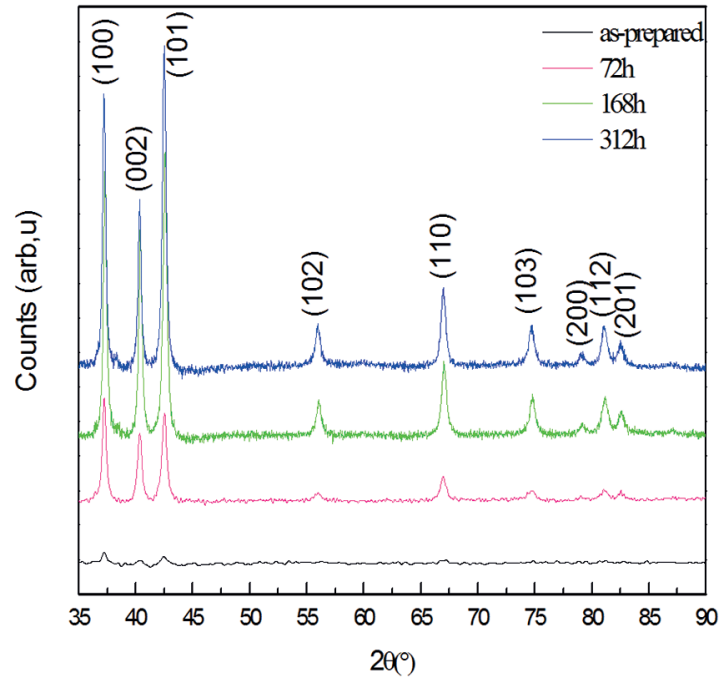

Figure 3: $\mathrm{X}$-ray diffraction patterns of $\mathrm{ZnO}$ thin films prepared after different aging time.

as coarsening or ripening. In this process, material dissolves from the surface of large particles and deposits on the initially narrow "necks" which join particles to each other and hence the grain size increases.

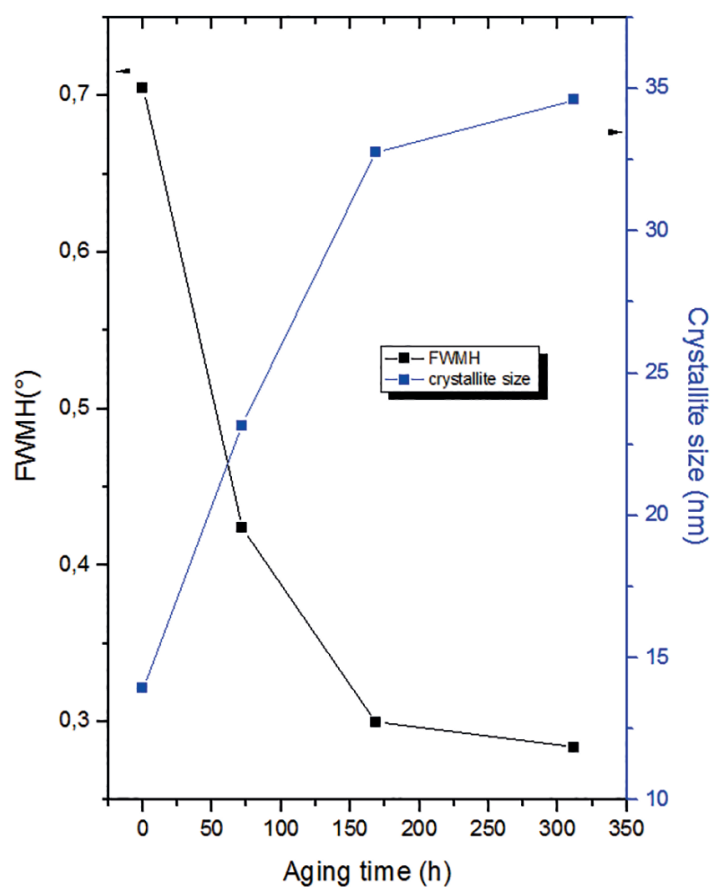

Figure 4: Variations of crystallite size and $\beta$ of $\mathrm{ZnO}$ thin films as a function of sol aging time. 


\subsection{Optical properties}

Figure 5 depicts the optical transmission spectra of $\mathrm{ZnO}$ films recorded in the wavelength region of 300-700 nm for different sol aging time. The deposited films are highly transparent with an average transmission exceeding 70-80 $\%$ in the visible range, which slightly improved with aging time. There has been an increase in optical transmittance. This increase is due to the decrease in surface roughness of films as confirmed by AFM images. Later these grains grow up in disordered manner resulting in scattering of light and a slight decrease in optical transmittance of the films. As shown in Figure 5, the aging time, from 0 to $168 \mathrm{~h}$, does not affect the strong absorption property of $\mathrm{ZnO}$ thin films in the ultraviolet range and the fundamental absorption edges of the samples all locate at $\sim 370 \mathrm{~nm}$ which corresponds to optical bandgap transition of $\mathrm{ZnO}$. Later, it was found that further increase in aging time resulted in a small variation in absorption edges.

In the direct transition materials such as $\mathrm{ZnO}$, the absorption coefficient $(\alpha)$ can be expressed by applying the Tauc model in the high absorption region ${ }^{41}$ :

$$
(\alpha h v)^{2}=A(h v-E g)
$$

where $\alpha$ denotes the optical absorption coefficient, $h$ is Planck's constant and $v$ is the frequency of the incident photon, Eg is the optical band gap and A is a constant for a direct transition. Assuming the absorption coefficient $\alpha \sim-$ $\mathrm{Ln}(\mathrm{T})$ corresponding to the direct band gap of the Wurtzite structure, a plot of $(\alpha h v)^{2}$ versus the photon energy hv yields in the sharp absorption edge for the high quality films by a linear $\mathrm{fit}^{42}$.

Figure 6 shows the plots of $(\alpha h v)^{2}$ versus hv for the $\mathrm{ZnO}$ thin films deposited from sol being aged for different time. Optical band gap (Eg) can be determined by a linear extrapolation of the $(\alpha h v)^{2}$ plot against $h v$ to the energy axis. The inset in Figure 6 indicates the variation of band gap energy with the sol aging time; its observed that an increase in optical energy gap from 3.19 to $3.25 \mathrm{eV}$ occurred when the sol aging time varied between 0 and $312 \mathrm{~h}$, respectively. We presumably attribute the variation of optical Eg with sol aging time to the improvement in the crystalline quality of the films, already proved by XRD results.

\section{Conclusion}

In summary, pure $\mathrm{ZnO}$ films have been successfully synthesized via sol-gel dip coating method on glass substrates. This process eliminates the addition of basic or acid solutions containing foreign elements, high temperature and complex systems. In the present contribution, the effects of aging time on the morphological, structural and optical properties of $\mathrm{ZnO}$ films were investigated systematically. Morphological analysis revealed that thin films prepared from aged sol were

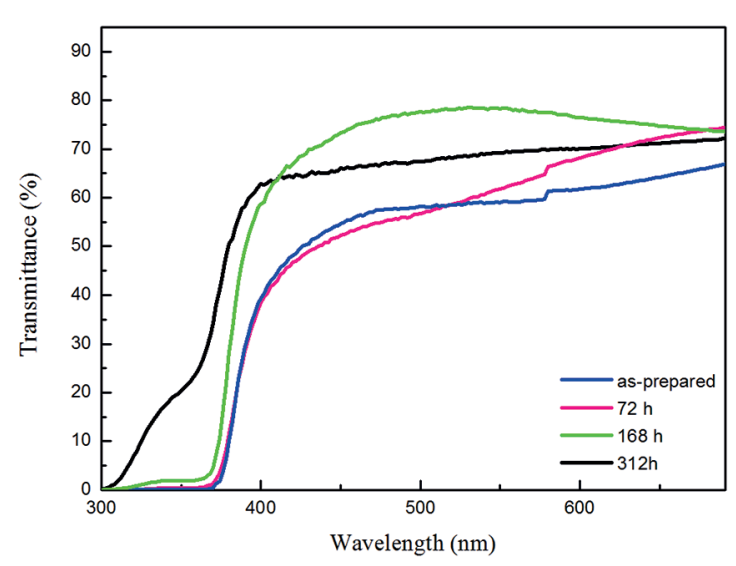

Figure 5: Optical transmission spectra of $\mathrm{ZnO}$ films for different aging time.

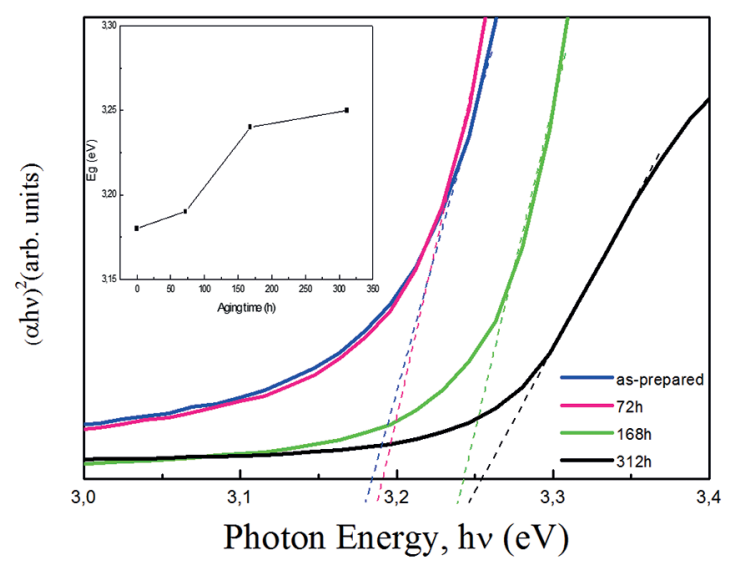

Figure 6: Plot of $(\alpha h v)^{2}$ vs. photon energy (hv) of $\mathrm{ZnO}$ film with different sol aging time. The inset represents band gap values obtained by extrapolating the linear part of the curves.

relatively smoother with minimum surface roughness and the heavily aged samples exhibits nanorods morphology. The obtained $\mathrm{ZnO}$ films exhibit wurtzite structure with random orientation and an apparent increase in crystallinity was observed with increasing sol aging time. Experimental results have shown that the prepared zinc oxide thin films by this method have higher crystallinity spectra as compared to other methods. Moreover, the optical transparency of films was significantly enhanced by aging the solution for longer times. An optimum sol aging time was determined for thin film formation providing a useful guideline for the process control purposes. These results meant that $\mathrm{ZnO}$ films prepared from the sol with longer aging time were still suitable for practical applications.

\section{References}

1. Suwanboon S, Ratana T, Ratana T. Effects of Al and Mn Dopant on Structural and Optical Properties of ZnO Thin Film Prepared by Sol-Gel Route. Walailak Journal of Science and Technology. 2007;4(1):111-121. 
2. Ghamsari MS, Radiman S, Hamid MAA, Mahshid S, Rahmani Sh. Room temperature synthesis of highly crystalline $\mathrm{TiO}_{2}$ nanoparticles. Materials Letters. 2013;92:287-290.

3. Xu S, Wang ZL. One-Dimensional ZnO Nanostructures: Solution Growth and Functional Properties. Nano Research. 2011;4(11):1013-1098.

4. Tari O, Aronne A, Addonizio ML, Daliento S, Fanelli E, Pernice P. Sol-gel synthesis of $\mathrm{ZnO}$ transparent and conductive films: A critical approach. Solar Energy Materials and Solar Cells. 2012;105:179-186.

5. Bitenc M, Orel ZC. Synthesis and characterization of crystalline hexagonal bipods of zinc oxide. Materials Research Bulletin. 2009;44(2):381-387.

6. Hosseinmardi A, Shojaee N, Keyanpour-Rad M, Ebadzadeh T. A study on the photoluminescence properties of electrospray deposited amorphous and crystalline nanostructured $\mathrm{ZnO}$ thin films. Ceramics International. 2012;38(3):1975-1980.

7. Li ZW, Gao W. Growth of zinc oxide thin films and nanostructures by wet oxidation. Thin Solid Films. 2007;515(7-8):3323-3329.

8. Berruet M, Pereyra CJ, Mhlongo GH, Dhlamini MS, Hillie KT, Vázquez M, et al. Optical and structural properties of nanostructured $\mathrm{ZnO}$ thin films deposited onto FTO/glass substrate by a solution-based technique. Optical Materials. 2013;35(12):2721-2727.

9. Vajargah PH, Abdizadeh H, Ebrahimifard R, Golobostanfard MR. Sol-gel derived $\mathrm{ZnO}$ thin films: Effect of amino-additives. Applied Surface Science. 2013;285(Pt B):732-743.

10. Chiu SH, Huang JCA. Chemical bath deposition of ZnO and $\mathrm{Ni}$ doped $\mathrm{ZnO}$ nanorod. Journal of Non-Crystalline Solids. 2012;358(17):2453-2457.

11. Khelladi MR, Mentar L, Beniaiche A, Makhloufi L, Azizi A. A study on electrodeposited zinc oxide nanostructures. Journal of Materials Science: Materials in Electronics. 2013;24(1):153-159.

12. Baka O, Azizi A, Velumani S, Schmerber G, Dinia A. Effect of $\mathrm{Al}$ concentrations on the electrodeposition and properties of transparent Al-doped $\mathrm{ZnO}$ thin films. Journal of Materials Science: Materials in Electronics. 2014;25(4):1761-1769.

13. Mentar L, Baka O, Khelladi MR, Azizi A, Velumani S, Schmerber $\mathrm{G}$, et al. Effect of nitrate concentration on the electrochemical growth and properties of $\mathrm{ZnO}$ nanostructures. Journal of Materials Science: Materials in Electronics. 2015;26(2):1217-1224.

14. Tu HF. Characterizations of Electrochemically Synthesized Zinc Oxide. [PhD thesis]. Kaohsiung: Department of Electrical Engineering, National Sun Yat-Sen University Kaohsiung; 2008.

15. Gao YF, Nagai M, Masuda Y, Sato F, Koumoto K. Electrochemical deposition of $\mathrm{ZnO}$ film and its photoluminescence properties. Journal of Crystal Growth. 2006;286(2):445-450.

16. Yi R, Zhou H, Zhang N, Qiu G, Liu X. Effects of specific salts on the morphologies of $\mathrm{ZnO}$ microstructures. Journal of Alloys and Compounds. 2009;479(2009):L50-L53.

17. Sofiani Z, Derkowska B, Dalasiński P, Wojdyła M, DabosSeignon S, Alaoui Lamrani M, et al. Optical properties of $\mathrm{ZnO}$ and $\mathrm{ZnO}: \mathrm{Ce}$ layers grown by spray pyrolysis. Optics Communications. 2006;267(2):433-439.
18. Benramache S, Ben Temam H, Arif A, Guettaf A, Belahssen O. Correlation between the structural and optical properties of Co doped $\mathrm{ZnO}$ thin films prepared at different film thickness. Optik - International Journal for Light and Electron Optics. 2014;125(7):1816-1820.

19. Kripal R, Gupta AK, Srivastava RK, Mishra SK. Photoconductivity and photoluminescence of $\mathrm{ZnO}$ nanoparticles synthesized via co-precipitation method. Spectrochimica Acta Part A: Molecular and Biomolecular Spectroscopy. 2011;79(5):1605-1612.

20. Addonizio ML, Aronne A, Daliento S, Tari O, Fanelli E, Pernice P. Sol-gel synthesis of $\mathrm{ZnO}$ transparent conductive films: The role of pH. Applied Surface Science. 2014;305:194-202.

21. Nian H, Hahn SH, Koo KK, Shin EW, Kim EJ. Sol-gel derived N-doped ZnO thin films. Materials Letters. 2009;63(26):2246-2248.

22. Li J, Xu J, Xu Q, Fang G. Preparation and characterization of $\mathrm{Al}$ doped $\mathrm{ZnO}$ thin films by sol-gel process. Journal of Alloys and Compounds. 2012;542(2012):151-156.

23. Xu L, Zheng G, Miao J, Xian F. Dependence of structural and optical properties of sol-gel derived $\mathrm{ZnO}$ thin films on sol concentration. Applied Surface Science. 2012;258(19):7760-7765.

24. Wang XH, Shi J, Dai S, Yang Y. A sol-gel method to prepare pure and gold colloid doped $\mathrm{ZnO}$ films. Thin Solid Films. 2003;429(1-2):102-107.

25. Cui L, Wang GG, Zhang HY, Sun R, Kuang XP, Han JC. Effect of film thickness and annealing temperature on the structural and optical properties of $\mathrm{ZnO}$ thin films deposited on sapphire (0001) substrates by sol-gel. Ceramics International. 2013;39(3):3261-3268.

26. Tsay CY, Lee WC. Effect of dopants on the structural, optical and electrical properties of sol-gel derived $\mathrm{ZnO}$ semiconductor thin films. Current Applied Physics. 2013;13(1):60-65.

27. Ghodsi FE, Absalan H. Comparative Study of ZnO Thin Films Prepared by Different Sol-Gel Route. Acta Physica Polonica A. 2010;118(4):659-664.

28. Foo KL, Kashif M, Hashim U, Liu WW. Effect of different solvents on the structural and optical properties of zinc oxide thin films for optoelectronic applications. Ceramics International. 2014;40(1 Pt A):753-761.

29. Ibrahim NB, Al-Shomar SM, Ahmad SH. Effect of aging time on the optical, structural and photoluminescence properties of nanocrystalline $\mathrm{ZnO}$ films prepared by a sol-gel method. Applied Surface Science. 2013;283:599-602.

30. Hosono E, Fujihara S, Kimura T, Imai H. Non-Basic Solution Routes to Prepare ZnO Nanoparticles. Journal of Sol-Gel Science and Technology. 2004;29(2):71-79.

31. Rani S, Suri P, Shishodia PK, Mehra RM. Synthesis of nanocrystalline $\mathrm{ZnO}$ powder via sol-gel route for dye-sensitized solar cells. Solar Energy Materials and Solar Cells. 2008;92(12):1639-1645.

32. Hosono E, Fujihara S, Kimura T, Imai H. Growth of layered basic zinc acetate in methanolic solutions and its pyrolytic transformation into porous zinc oxide films. Journal of Colloid and Interface Science. 2004;272(2):391-398.

33. Kanade KG, Kale BB, Aiyer RC, Das BK. Effect of solvents on the synthesis of nano-size zinc oxide and its properties. Materials Research Bulletin. 2006;41(3):590-600. 
34. Li Y, Xu L, Li X, Shen X, Wang A. Effect of aging time of $\mathrm{ZnO}$ sol on the structural and optical properties of $\mathrm{ZnO}$ thin films prepared by sol-gel method. Applied Surface Science. 2010;256(14):4543-4547.

35. Cullity BD, Stock SR. Elements of X-Ray Diffraction. $3^{\text {rd }}$ ed. Cambridge: Pearson; 2001.

36. Dutta M, Mridha S, Basak D. Effect of sol concentration on the properties of $\mathrm{ZnO}$ thin films prepared by sol-gel technique. Applied Surface Science. 2008;254(9):2743-2747.

37. Fathollahi V, Amini MM. Sol-gel preparation of highly oriented gallium-doped zinc oxide thin films. Materials Letters. 2001;50(4):235-239.
38. Singh N, Dhruvashi, Kaur D, Mehra RM, Kapoor A. Effect of Ageing in Structural Properties of $\mathrm{ZnO}$ Nanoparticles with $\mathrm{pH}$ Variation for Application in Solar Cells. The Open Renewable Energy Journal. 2012;5:15-18.

39. Brinker CJ, Scherer GW. Sol-gel science; the physics and chemistry of sol-gel processing. Cambridge: Academic Press; 1990. 912 p.

40. Wright JD, Sommerdijk NAJM. Sol-Gel Materials: Chemistry and Applications. Amsterdam: Gordon and Breach Science; 2001.

41. Tauc J, Menth A. States in the gap. Journal of Non-Crystalline Solids. 1972;8-10:569-585.

42. Shan FK, Yu YS. Band gap energy of pure and Al-doped $\mathrm{ZnO}$ thin films. Journal of the European Ceramic Society. 2004;24(6):1869-1872. 